\title{
Intracranial brain stimulation and suppression of behavior
}

Hungry rats were trained to lever press for food on a variable interval schedule. Subsequent to attaining stable rates, stimulation of either the nucleus Ventralis Postero Lateralis of the thalmus, or of the Central Grey substance was introduced on a response contingent basis. The effect of such stimulation on the response rate for the food reinforcement provided an index of the aversiveness of the brain stimulation. For each animal, lever pressing rate is a decreasing exponential function of the intensity of stimulation either to the VPL or the CG. Once behavior has been suppressed, rate of retum to baseline is an inverse, monotonic function of punishment intensity.

This study investigates the effects of brain stimulation used as punishment on a concurrent schedule where the animal is trained to lever press for food on a VI 1 schedule and subsequently the brain stimulation is introduced on a response contingent basis. Two brain loci were investigated, Nucleus Ventralis Postero Lateralis (VPL) and the Central Grey substance (CG). The VPL was selected because it functions as a major somatosensory relay nucleus; stimulation of this a rea would presumably mimic diffuse stimulation of the body surface. The CG was chosen on the basis of prior reports that stimulation at this site has aversive consequences (Olds \& Olds, 1962).

\section{Method}

Four naive male Sprague-Dawley rats with chronic indwelling stimulating electrodes in the brain served as Ss. The apparatus was a modified Gerbrands animal chamber equipped with a bar and dipper to deliver a liquid diet of sweetened milk and vitamins. Stimulation equipment was Tektronix 160 series pulse and waveform generators with the output fed through a 5-1 step-up isolation transformer. This equipment was used to generate $0.5 \mathrm{sec}$. trains of pulses of $1 \mathrm{msec}$. duration and frequency of 60 per sec. Stimulation current was calculated from the voltage drop across a $100 \mathrm{ohm}$ series resistor. Electrodes were enameled stainless steel insect pins (N. 00) and were implanted stereotaxically using the deGroot coordinate system (1959).

Ss were allowed one week recovery following implantation and were then started on a conditioning procedure which resembled that used in studies of peripheral punishment (Appel \& Peterson, 1965). They were maintained on $22 \mathrm{hr}$. food deprivation. Conditioning was begun with CRF and the animals were subsequently shifted to VI 1.
Stitnulation to a brain locus was administered for $0.5 \mathrm{sec}$. contingent on each lever pressing response, beginning the stimulation procedure with the lowest intensity (see Fig. 1). The same intensity was used throughout a day of punishment, i.e., for the entire $1 / 2 \mathrm{hr}$. session.

The animals were always allowed to work back to their pre-punishment baseline rate following a day of stimulation, thus the sequences appear as one in which the brain stimulation is administered approximately one day out of each week.

\section{Results}

The results will be presented in terms of three major punishment phenomena: suppression, adaption, and post-punishment recovery.

Suppression. Figure 1 shows the mean performance of each rat during sessions of VPL stimulation. The dependent variable, percent unpunished rate, is a ratio of the number of responses during each day of stimulation ( $x$ 100) divided by the mean number of responses on the two days preceding each stimulation day. Thus, Ss are equated with respect to unpunished baseline rate.

It can be seen that response rate for rats 231,263 , and 265 is a decreasing monotonic function of shock intensity. This agrees with earlier studies involving grid shock rats. Rat 264 is atypical. Even at the lowest intensity complete suppression appears to occur. Histological examination showed the electrode in this $\mathrm{S}$ to have penetrated VPL with the stimulating tip lying in

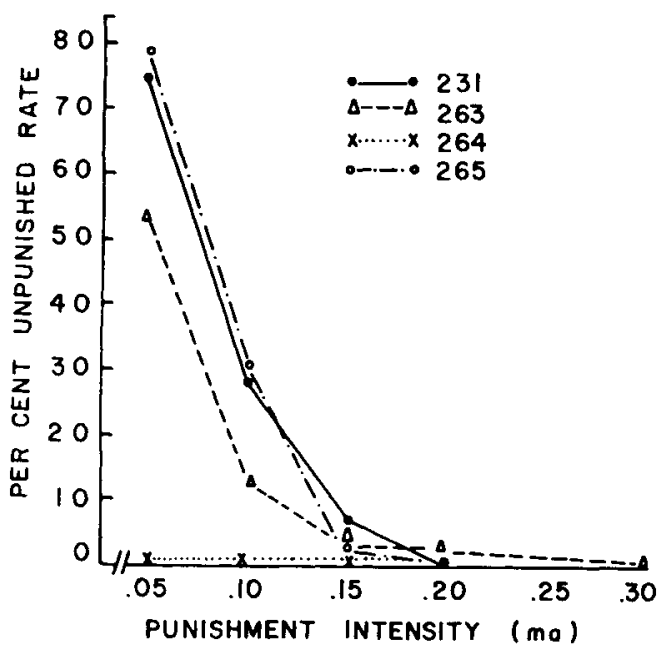

Fig. 1. Mean performance during VPL stimulation. 
the Medial Lemniscus. All other electrode placements were accurate.

Adaption. Figure 2 presents cumulative curves from a single $\mathrm{S}$ with stimulation of the VPL and CG. With CG stimulation of $0.025 \mathrm{ma}$ there is some evidence of within session recovery. This was not observed at higher CG intensities nor with any intensity of VPL stimulation.

Post-punishment. Average rates of bar-pressing during stimulation sessions and for several subsequent sessions are shown in Fig. 3. The time to recover to baseline rate on the VI 1 schedule following VPL stimulation is an increasing function of stimulus intensity. At the same time, the degree of suppression is increasing with stimulus intensity so that the beginning point from which $S$ must recover is progressively lower.

The principle result of this investigation is that, in a punishment situation, response contingent stimulation of certain brain structures suppresses behavior in much the same manner as does peripherally administered electric shock. The use of brain stimulation seems to offer a means of avoiding some of the complications common to many techniques of peripheral stimulation which may be responsible in whole or in
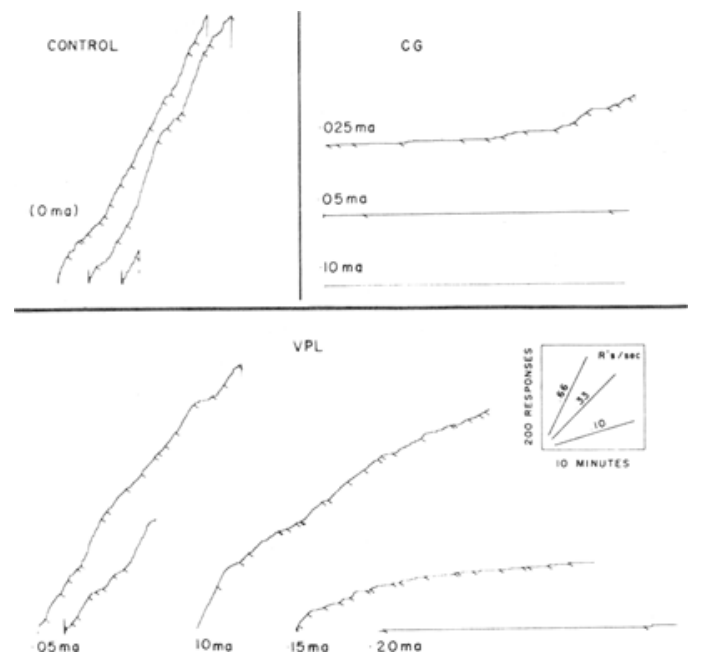

Fig. 2. Cumulative curves for a single $S$ with VPL and CG stimulation.

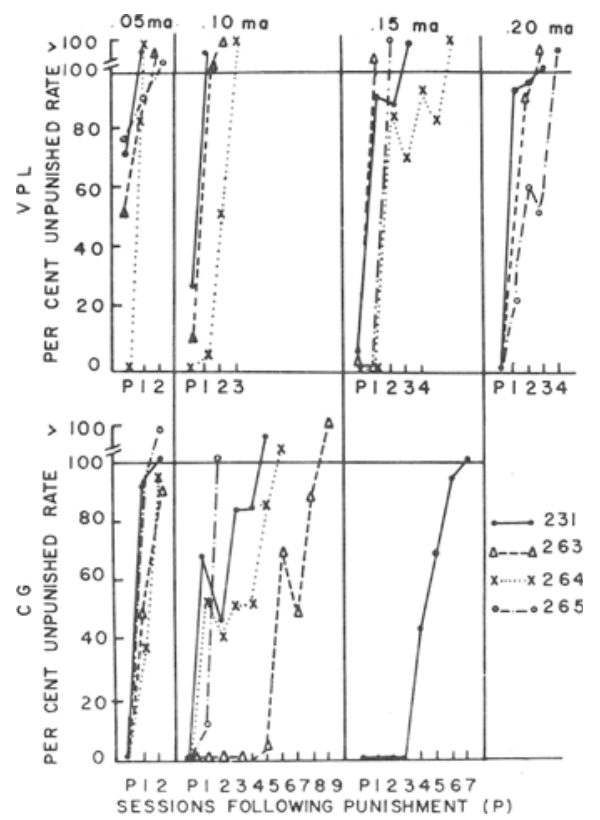

Fig. 3. Average bar-pressing rate during stimulation sessions and subsequent sessions.

part for adaption as well as for many other problems in punishment research, i.e., burning of the skin, physiological adaption of pain receptors and changes in electrical resistance.

\section{References}

Appel, J. B. Punishment and shock intensity. Science, 1963, 141, 528-529.

Appel, J. B., \& Peterson, N. J. Punishment: Effects of shock intensity on response suppression. Psychol. Rep., 1965, 16, 721730.

Church, R. M. The varied effects of punishment on behavior. Psychol. Rev., 1963, 70, 369-402.

Coons, E. C. Motivational correlates of eating elicited by electrical stimulation in the hypothalmic feeding area. Unpublished doctoral dissertation, Yale University, 1963.

de Groot, J. The rat forebrain in stereotaxic coordinates. Verh. Kon. Ned. Akad. Wet., B. Naturkunde, 1959, 52, 1-40.

Delgado, J. M. R., Roberts, W. W., \& Miller, N. E. Learning motivated by electrical stimulation of the brain. Amer. J. Physiol., 1954, 179, 587-593.

\section{Notes}

1. Now at the University of Chicago Dept. of Psychiatry.

2. Supported by USPHS Grant M4163 and NSF Grant GB3216. 